SILVA WF; MARQUES DJ; SILVA EC; BIANCHINI HC; ISHIMOTO FA; PEREIRA JÚNIOR MJF. 2015. Diagnóstico da produção de hortaliças na região metropolitana de Belo Horizonte. Horticultura Brasileira 33: 368-372. DOI: http://dx.doi.org/10.1590/S0102-053620150000300015

\title{
Diagnóstico da produção de hortaliças na região metropolitana de Belo Horizonte
}

\author{
Wellington F Silva ${ }^{1}$; Douglas J Marques ${ }^{1}$; Ernani C Silva ${ }^{2}$; Hudson C Bianchini ${ }^{1}$; Fábio A Ishimoto ${ }^{1}$; \\ Marlon JF Pereira Júnior ${ }^{1}$ \\ 'Universidade de Alfenas, UNIFENAS, Alfenas-MG, Brasil; wferrari250@yahoo.com.br; douglas.marques@unifenas.br; hudson. \\ bianchini@unifenas.br; fabioishimoto@yahoo.com.br; marlonjsk812@hotmail.com; ${ }^{2}$ Universidade Federal de São João del-Rei, UFSJ, \\ Sete Lagoas-MG, Brasil; clarete@ufsj.edu.br
}

\section{RESUMO}

A cadeia produtiva de hortaliças da região metropolitana de Belo Horizonte caracteriza-se pelo cultivo de hortaliças tuberosas, herbáceas e frutos, sendo considerado um dos cinturões verdes do estado de Minas Gerais. Este trabalho teve como objetivo realizar um diagnóstico da situação atual dos produtores dessa região, analisando aspectos de produção, comercialização e caracterização dos produtores. A coleta dos dados foi feita através de um questionário estruturado aplicado in loco no período de janeiro a dezembro de 2013 para um grupo representativo de produtores, indicados pela EMATER-MG. Foi feita uma avaliação quantitativa dos dados apresentada na forma de figuras e tabelas. Verificou-se que na região metropolitana a maioria dos produtores de hortaliças possui idade superior a 39 anos, basicamente com grau de escolaridade fundamental, sendo que a principal hortaliça cultivada é a alface. Observou-se que as hortaliças são comercializadas na região metropolitana diretamente ao consumidor final. Desse modo, o estudo contribuiu para ampliar a compreensão a respeito da produção e comercialização das hortaliças. Com base nos dados obtidos sugerem-se estudos futuros comparativos entre diferentes regiões do estado de Minas Gerais.

Palavras-chave: Olericultura, cinturão verde, diagnóstico, comercialização.

\begin{abstract}
Diagnosis of vegetable production in the metropolitan region of Belo Horizonte, Brazil

The production chain of vegetables in the metropolitan region of Belo Horizonte is characterized by the cultivation of tuberous vegetables, herbs and fruits, considered one of the green belts of the state of Minas Gerais, Brazil. This study aimed to obtain a diagnosis of the current situation of producers in that region, analyzing aspects of production, marketing and characterization of producers. The research was carried out using a structured questionnaire applied in situ from January to December 2013 within a representative group of producers indicated by EMATER-MG. A quantitative evaluation of the research was made and presented in the form of figures and tables. Based on the obtained information, most of metropolitan vegetable producers were over 39 years old, basically with elementary education level, and the main grown vegetable is lettuce. The commercialization of the vegetables was carried out in the metropolitan region directly to the final consumer. Thus, the study contributed to expand the understanding of production and commercialization of vegetables. Based on the obtained information, the authors suggest comparation between different regions of Minas Gerais could be carried out by further studies.
\end{abstract}

Keywords: Vegetable crops, greenbelt, diagnosis, commercialization.

(Recebido para publicação em 29 de maio de 2014; aceito em 20 de março de 2015) (Received on May 29, 2014; accepted on March 20, 2015)

\begin{abstract}
A globalização da economia tem causado alterações em todos os elos da cadeia produtiva brasileira de hortaliças, ao mesmo tempo em que tem possibilitado avanços tecnológicos e estruturais. Essa mudança expõe os gargalos que ensejam superação para melhorar a sua competitividade (Melo \& Vilela, 2014).

Nos últimos dez anos a produção de hortaliças no país aumentou 33\% enquanto a área plantada foi reduzida em $5 \%$ e houve um incremento na pro-
\end{abstract}

dutividade de $38 \%$. A maior parte da produção concentra-se nas regiões Sul e Sudeste, onde $60 \%$ das plantações ficam próximas aos grandes centros consumidores, os chamados cinturões verdes. As propriedades são de exploração familiar com menos de 10 hectares os quais são utilizados intensivamente. Os outros $40 \%$ restantes, próximos a propriedades pequenas, médias e grandes, além de fazendas empresas (Camargo Filho et al., 2010).

Consideradas mais lucrativas que outras culturas, como as de grãos, por exemplo, as hortaliças têm uma realidade diferente e o sucesso dos negócios relativos a esse grupo de alimentos depende de muitos fatores. Deve-se considerar que as hortaliças são culturas temporárias que necessitam de um investimento inicial maior, variando em função da espécie, região e época de cultivo. Além disso, é difícil prever todas as medidas necessárias em uma atividade sujeita a tantos "altos e baixos", com diferenças tão marcantes de preço de 
uma hortaliça para outra (Anuário..., 2014). Para o produtor, as atividades hortícolas têm permitido viver razoavelmente bem com uma pequena área plantada, ressaltando-se os atributos de qualidade e uma alta produtividade, fatores fundamentais e determinantes de melhor rentabilidade nessa atividade (Villela \& Henz, 2000).

Parte importante no processo de comercialização são os canais de distribuição de frutas e hortaliças, onde ainda predominam as centrais de abastecimento (CEASA), mas com uma participação crescente e forte dos supermercados como meios de se fazer chegar ao consumidor final, frutas e hortaliças para a sua alimentação (Accarini et al., 2000). A feira livre é uma forma direta de comercialização muito utilizada pelos produtores e consumidores, pois não há presença de intermediários. Com isso os produtores têm uma margem maior de rendimento, que implica também na necessidade de maior profissionalização (Grande et al., 2003).

A produção de hortaliças no Brasil está em torno de 18 mil toneladas, com área plantada de 800 mil hectares e produtividade média de 23 toneladas por hectare, o que é equivalente a 94 kg habitante ano (Anuário..., 2014). O estado de Minas Gerais é o segundo maior produtor de hortaliças do país, com área plantada superior a $110 \mathrm{mil}$ hectares e volume produzido acima de 30 mil toneladas em 2013, em 204 municípios. Esta atividade gera $20 \mathrm{mil}$ empregos diretos, envolvendo aproximadamente 2 mil produtores individuais (CEASAMINAS, 2014). As culturas de batata e de morango se destacam com produção de 900 mil e 33 mil toneladas, respectivamente, assegurando a liderança do estado no ranking nacional desses produtos. A produção de cenoura, com expressivas 320 mil toneladas, completa este cenário, colocando Minas Gerais na vice-liderança de produção deste produto devido à expansão da área plantada e à utilização de tecnologias avançadas (Neves, 2012).

No cinturão verde da cidade de Belo Horizonte, o cultivo de hortaliças segue o padrão predominante no estado de Minas Gerais. De acordo com CEASAMINAS (2014), a região metropolitana é constituída por 34 municípios, com produção média de 44 mil toneladas de hortaliças por ano, correspondendo aproximadamente a $16 \%$ da produção do estado.

O conhecimento dos canais de comercialização e a articulação cooperada entre os elos da cadeia, respeitando as características dos produtos e do mercado, servem de ferramenta para melhor organização e eficiência do sistema.

Sendo assim, o presente trabalho teve como objetivo analisar a cadeia produtiva de hortaliças da região metropolitana de Belo Horizonte no estado de Minas Gerais.

\section{MATERIAL E MÉTODOS}

O experimento foi realizado na UNIFENAS, localizada em Alfenas no sul de Minas Gerais. A pesquisa teve como base a entrevista dos agentes atuantes no cenário da produção de hortaliças. A coleta dos dados foi feita através de um questionário estruturado, aplicado in loco no período de janeiro a dezembro de 2013, para um grupo representativo de 30 produtores indicados pela EMATER-MG. O caráter descritivo do trabalho foi determinado, principalmente, pela finalidade de registrar, analisar e relacionar as variáveis sem manipulá-las. Com o objetivo de obter o maior número possível de questionários preenchidos, foram utilizadas algumas estratégias na sua aplicação, tais como o contato pessoal com os entrevistados e contato por telefone. Quanto à forma escolhida para o preenchimento do questionário, levou-se em consideração o caráter opinativo espontâneo do entrevistado. Pesquisas de opinião devem abordar atitudes, pontos de vista e preferências que as pessoas têm a respeito de algum assunto, com o objetivo de tomar decisões (Cervo, 2002).

As perguntas que constaram no questionário foram: 1) idade dos trabalhadores rurais; 2) comercialização das hortaliças produzidas no cinturão verde de Belo Horizonte; 3) atualização dos produtores de hortaliças na Região Metropolitana de Belo Horizonte (RMBH); grau de escolaridade dos produtores de hortaliças; 4) produtores que recebem serviço de consultoria nas propriedades; 5) principais hortaliças produzidas na região metropolitana de Belo Horizonte; 6) agricultores que realizam análise de solo; 7) fertilizantes utilizados para a produção das principais hortaliças; 8) aplicação de adubação foliar pelos produtores de hortaliças; 9) forma de divulgação da produção das hortaliças.

De acordo com Gil (2007), o principal objetivo das pesquisas que têm abordagem descritiva é a caracterização de determinada população pelo estabelecimento de relações entre as variáveis estudadas. Uma das características mais significativas desse tipo de abordagem é a utilização de técnicas padronizadas de coleta de dados com utilização de questionário. Visando obter o maior número possível de questionários preenchidos foi feito contato pessoal com os entrevistados e, quando isso não foi possível, o questionário foi preenchido através de contato por telefone. A fim de que os entrevistados expressassem livremente sua opinião, o questionário foi preenchido levando-se em consideração o caráter opinativo do entrevistado. A pesquisa de opinião deve procurar identificar atitudes, pontos de vista e preferências que as pessoas têm a respeito de algum assunto, conforme descreve Cervo (2002).

Segundo Richardson (2007), o método quantitativo representa, em princípio, uma garantia de precisão dos resultados, evitando distorções de análise e interpretação. Sendo assim, o método quantitativo pode ser muito utilizado no desenvolvimento das pesquisas descritivas e também empregado no desenvolvimento das pesquisas de opinião.

As informações obtidas foram submetidas à análise estatística descritiva como ferramenta de organização dos dados. Através de figuras e tabelas foram computadas as frequências absoluta e percentual, com a finalidade de extrair informações da amostra. O software Excel foi utilizado para organização dos dados (Ferreira, 2009).

\section{RESULTADOS E DISCUSSÃO}

A Figura 1 apresenta a idade dos 
trabalhadores que cultivam hortaliças. Observa-se que a maior porcentagem de indivíduos está situada no grupo de idade superior a 39 anos. Estes resultados podem estar relacionados ao êxodo rural, tendo em vista que o trabalho no campo não está sendo suficientemente atrativo para fixar os indivíduos mais jovens. O cenário é preocupante, pois poderá provocar uma possível falta de trabalhadores envolvidos com as atividades rurais, no decorrer dos anos. Este resultado corrobora com o obtido por Camarano \& Abramovay (1998) que, ao abordarem o movimento migratório ocorrido no Brasil, nos últimos 50 anos, demostraram uma elevada tendência de saída da população rural para as cidades urbanas. Esta tendência tem feito do meio rural um ambiente menos propício para a fixação da população mais jovem, prevalecendo a presença de uma população predominantemente idosa e masculina no campo, o que compromete ainda mais o seu desenvolvimento.

Uma mudança no perfil do fluxo migratório rural advindo na década de 1950 mostra que o ponto máximo da migração acontecia na faixa etária de 30 a 39 anos. Já no ano 1990 predominou a saída de jovens do sexo masculino e feminino da faixa etária entre 20 a 24 anos e 15 a 19 anos, respectivamente. Atualmente observa-se uma tendência de acréscimo do fluxo migratório de jovens com idade inferior a 20 anos. Vários fatores têm contribuído para agravar este quadro, entre eles destacam-se a falta de assistência técnica para orientação dos produtores rurais, falta de crédito para se iniciar alguma atividade, entre outros (Campanhola \& Silva, 2000; Sena et al., 2013).

Pesquisas apontam que cada vez mais os jovens provenientes da área rural têm optado pelo trabalho urbano. Esta migração dos jovens para a área urbana tem contribuído para aumentar alguns problemas como, aumento na procura por emprego na zona urbana, redução de propriedades agrícola classificados como agricultura familiar, falta de mão de obra no campo, entre outras. Considerando a tendência de saída dos jovens da zona rural para zona urbana, o envelhecimento dos indivíduos que permanecem trabalhando no campo

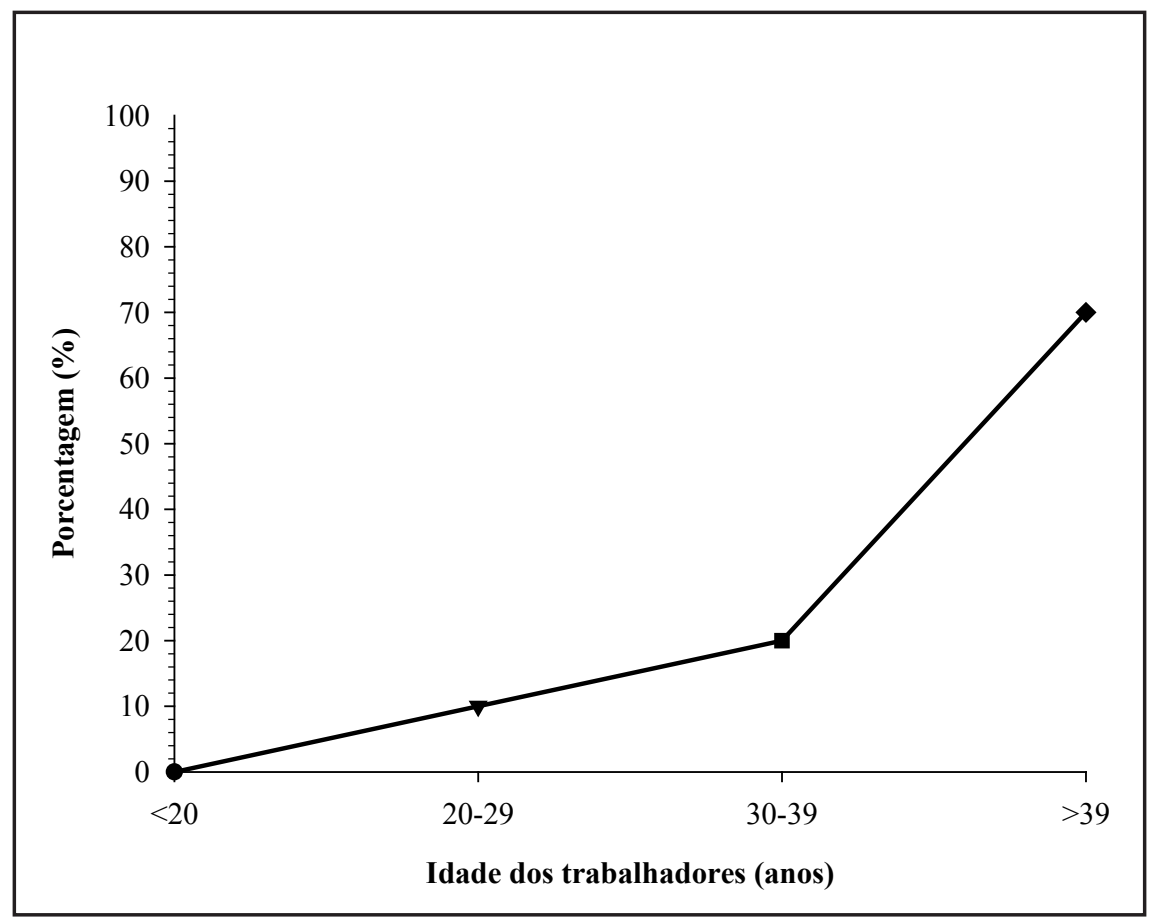

Figura 1. Idade dos trabalhadores rurais em anos (age of rural workers in years). Alfenas, UNIFENAS, 2014.

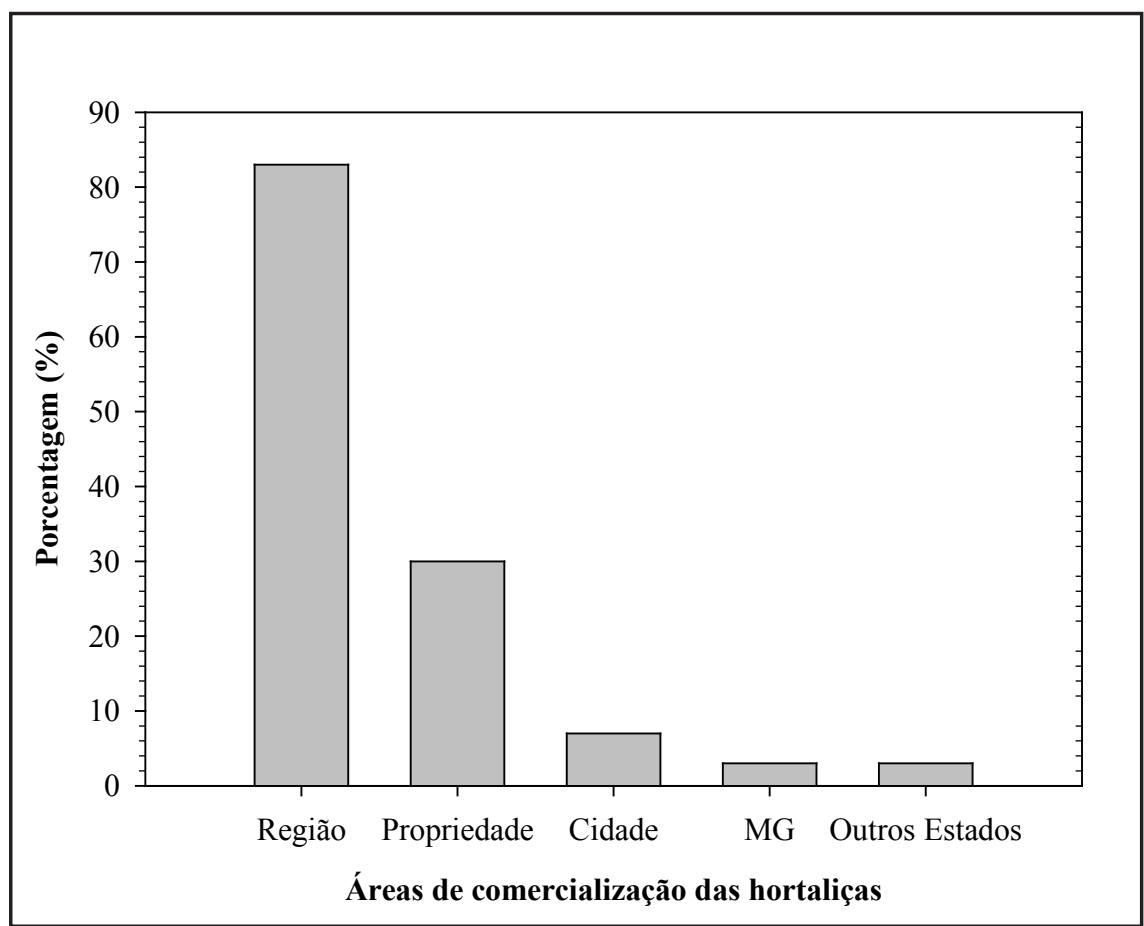

Figura 2. Comercialização das hortaliças produzidas no cinturão verde de Belo Horizonte (marketing of vegetables produced in the green belt of Belo Horizonte). Alfenas, UNIFENAS, 2014.

pode acentuar um declínio no número de pequenas propriedades rurais, uma vez que filhos desses produtores, que são os sucessores naturais, não se interessam pela atividade dos pais, ameaçando a continuidade do processo produtivo (Ferrari, 2004).

A Tabela 1 apresenta o grau de escolaridade dos produtores rurais e, pelos dados, notou-se que $60 \%$ dos produtores 
Tabela 1. Grau de escolaridade dos produtores de hortaliças (level of the growers education). Alfenas, UNIFENAS, 2014.

\begin{tabular}{lcc}
\hline Grau de escolaridade & Frequência & Valor (\%) \\
\hline Analfabeto & 1 & 3,3 \\
Ensino fundamental & 18 & 60,0 \\
Ensino médio & 10 & 33,3 \\
$3^{\circ}$ Grau & 1 & 3,3 \\
\hline Total & 30 & 100,0 \\
\hline
\end{tabular}

Tabela 2. Produtores que recebem serviço de consultoria nas propriedades (producers receiving consulting service in the farms). Alfenas, UNIFENAS, 2014.

\begin{tabular}{lcc}
\hline Órgãos de consultoria & Frequência & Valor (\%) \\
\hline Emater-MG & 26 & 96,3 \\
Prefeitura Belo Horizonte-MG & 4 & 14,8 \\
Técnico de revendas & 2 & 7,4 \\
\hline Total & 27 & 118,5 \\
\hline
\end{tabular}

Tabela 3. Principais hortaliças produzidas da região metropolitana de Belo Horizonte (main vegetables produced in the metropolitan region of Belo Horizonte, Brazil). Alfenas, UNIFENAS, 2014.

\begin{tabular}{lcc}
\hline Hortaliças & Frequência & Valor (\%) \\
\hline Cenoura & 1 & 3,3 \\
Tomate & 3 & 10,0 \\
Pimentão & 1 & 3,3 \\
Pepino & 1 & 3,3 \\
Feijão-vagem & 1 & 3,3 \\
Alface & 18 & 60,0 \\
Couve chinesa & 1 & 3,3 \\
Agrião & 1 & 3,3 \\
Repolho & 1 & 3,3 \\
Quiabo & 1 & 3,3 \\
Chuchu & 1 & 3,3 \\
\hline Total & 30 & 100,0 \\
\hline
\end{tabular}

possuem nível fundamental. Estes dados demonstram que os produtores atuantes neste cenário têm um baixo nível educacional. Este menor grau de escolaridade pode afetar todo o processo produtivo de hortaliças, em função da limitação na aplicação dos conhecimentos técnicos e comercialização, o que afeta a receita da propriedade. Quando maior o nível intelectual do individuo, maior será a facilidade em administrar a propriedade rural favorecendo a criação de estratégias para períodos de maior flutuação nos preços das oleráceas. Assim, os produtores rurais com maior grau de escolaridade estão mais aptos às mudanças e comercialização das hortaliças. O serviço de consultoria da EMATER-MG tem levado ao produtor rural formas de promover o desenvolvimento sustentável, por meio da assistência técnica e extensão rural atendendo principalmente pequenos e médios produtores, já que estes são carentes de incentivo e assistência técnica (Guimarães, 2013).

Em outros casos, a assistência é realizada por técnicos especializados, sendo monitorada apenas pelos vendedores de insumos ou técnicos de revendas (Grande et al., 2003). O principal objetivo da consultoria é fazer com que os agricultores possam ter acesso a uma orientação técnica adequada, que só ocorre se houver a relação direta entre o técnico e o agricultor. Nota-se também que é necessário estabelecer projetos pilotos, onde o responsável técnico fará seu plano de atividades em conjunto com os agricultores, para que ambos conquistem resultados satisfatórios (Caporal \& Ramos, 2013).

A Tabela 3 apresenta as principais hortaliças produzidas da Região Metropolitana de Belo Horizontes (RMBH). Com base nos dados coletados constatou-se que os produtores rurais cultivam 32 espécies de oleráceas, observando ainda que a maioria dos produtores está na atividade de produção a mais de 4 anos. A principal hortaliça produzida é a alface $(60 \%)$ seguida do tomate $(10 \%)$ e das outras hortaliças com menor porcentagem como a cenoura, pimentão, pepino, feijão-vagem, couve-chinesa, agrião, repolho, quiabo e chuchu respectivamente. O maior plantio de alface pode estar relacionado a fatores tais como a forma de comercialização, sendo possível a venda direta para o consumidor final, o ciclo curto da cultura, que garante maior receita e também, fato de estar próximo a um grande centro urbano como Belo Horizonte o que favorece a comercialização (Branco, 2001). Já para o tomate, por ser um produto altamente perecível, com ampla flutuação de preço, há necessidade de se avaliar os riscos econômicos e as dificuldades técnicas, para evitar eventuais prejuízos para o produtor (Sanino et al., 2003). O cinturão verde da RMBH está localiza- 
do na Ceasa em Contagem-MG, com acesso facilitado para o escoamento da produção das hortaliças e locação produtiva nos modelos de análise regional. A proximidade com o centro urbano facilita o escoamento da produção para o mercado consumidor de forma mais econômica e rápida, favorecendo o fornecimento de produtos de qualidade e em quantidades suficientes.

A respeito da comercialização das hortaliças produzidas no cinturão RMBH (Figura 2) 83,3\% dos entrevistados responderam que realizam a comercialização na própria região metropolitana, 30\% da comercialização das hortaliças é realizada diretamente em suas propriedades, $6,7 \%$ na cidade em que residem, sendo que 3,3\% dos produtos comercializados têm origem em outros estados do Brasil.

Os resultados obtidos na pesquisa evidenciam que a maioria dos produtores de hortaliças possui idade superior a 39 anos, basicamente com grau de escolaridade fundamental, sendo que a principal hortaliça cultivada é a alface. Observou-se que as hortaliças são comercializadas na região metropolitana diretamente ao consumidor final. $\mathrm{O}$ serviço de consultoria da EMATER-MG tem trabalhado com o produtor na difusão de tecnologia.

Desse modo, o estudo contribuiu para ampliar a compreensão a respeito da produção e comercialização das hortaliças. Com base nos dados obtidos sugerem-se estudos futuros comparativos entre diferentes regiões do estado de Minas Gerais.

\section{REFERÊNCIAS}

ACCARINI JH; MAZOCATO MA; COSTA OGP; LUENGO RFA. 2000. Hortícolas modernização necessária. Agroanalysis 20: 41-46.

ANUÁRIO BRASILEIRO DE HORTALIÇAS. 2014. Brazilian Vegetable Yearbook. Santa Cruz do Sul: Editora Gazeta Santa Cruz. 88p.

BRANCO RBF. 2001. Avaliação de cultivares e épocas de cultivo de alface nas condições de solo e hidroponia, em ambiente protegido. Jaboticabal: UNESP. 80p. (Dissertação mestrado).

CAMARANO AA; ABRAMOVAY R. 1998. Êxodo rural, envelhecimento e masculinização no Brasil: Panorama dos últimos 50 anos. Brasília: Instituto de Pesquisa Econômica Aplicada, 23p.

CAMARGO FILHO WP; CAMARGO FP; ALVES HS. 2010. Algumas sugestões para a expansão da agropecuária orgânica no estado de São Paulo. Informações Econômicas 37: 50-61.

CAMPANHOLA C; SIlva JG. 2000. Desenvolvimento local e a democratização dos espaços rurais. Cadernos de Ciência \& Tecnologia 17: 11-40.

CAPORAL FR; RAMOS LF. 2013. Da Extensão Rural Convencional à Extensão Rural para o Desenvolvimento Sustentável: Enfrentar Desafios para Romper a Inércia. Brasília, 2006. Texto em Fase de Publicação. Disponível em: http://www.pronaf.gov.br/ dater/arquivos/0730612230.pdf. Acessado em 23 maio de 2013.

CEASAMINAS. 2014. Perfil da oferta no mercado livre do produtor. Disponível em http://www.ceasaminas.com.br

CERVO AL. 2002. Metodologia cientifica. São Paulo: Prentice Hall. 150p.

FERREIRA DF. 2009. Estatística Básica. Lavras: UFLA. $105 \mathrm{p}$.

FERRARI DL. 2004. Dilemas e estratégias dos jovens rurais: ficar ou partir. Estudos Sociedade e Agricultura 12: 237-271.

GIL AC. 2007. Como elaborar projetos de pesquisa. São Paulo: Atlas. 120p.

GRANDE L.; LUZ JMQ; MELO B; LANA RMQ; CARVALHO JOM. 2003. O cultivo protegido de hortaliças em Uberlândia-MG. Horticultura Brasileira 21: 241-244.

GUIMARÃES BC. 2013. Assistência técnica e extensão rural para a agricultura familiar. Empresa de Assistência Técnica e Extensão Rural do Estado de Minas Gerais. Disponível em: http://www.emater.mg.gov. br/portal.cgi?flagweb=site_tpl_paginas internas\&id=924. Acessado em 23 maio 2013.

MELO PCT; VILELA NJ. 2014. Importância da cadeia produtiva brasileira de hortaliças. In: REUNIÃO ORDINÁRIA DA CÂMARA SETORIAL DA CADEIA PRODUTIVA DE HORTALIÇAS, 13, Brasília, 2007. Palestra... Brasília-DF: Ministério da Agricultura, Pecuária e Abastecimento, 2007. Disponível em: http://www.abhorticultura.com.br/ downloads/cadeia_produtiva.pdf.

NEVES WS. 2012. Empresa de Pesquisa Agropecuária de Minas Gerais, Belo Horizonte, 2012. Disponível em: http://www. epamig.br/index.php?option=com_content\&t ask=view\&id=187\&Itemid=57. Acessado em 20 de maio de 2013.

OLIVEIRA EQ; SOUZA RJ; CRUZ MCM; MARQUES VB; FRANÇA AC. 2010. Produtividade de alface e rúcula em sistema consorciado, sob adubação orgânica e mineral. Horticultura Brasileira 28: 36-40.

RICHARDSON RJ. 2007. Pesquisa social: métodos e técnicas. $3^{\mathrm{a}}$ ed. São Paulo: Atlas. $250 \mathrm{p}$.

SANINO A; CORTEZ LB; MEDEROS BT. 2003. Vida de prateleira do tomate (Lycopersicum esculentum), variedade "Débora", submetido a diferentes condições de resfriamento. In: WORKSHOP DE TOMATES. PERSPECTIVAS E PESQUISAS. Anais... Campinas: UNICAMP. CD-ROM.

SCHULTZ TW. 1975. The value of the ability to deal with disequilibria. Journal of Economics Literature 13: 827-846.

SENA EOA; OLALDE AR; SILVA PSO. 2013. Educação e permanência no campo: Os desafios dos jovens rurais no município de Governador Mangabeira, Bahia, Brasil. Cadernos de Agroecologia 8: 1-5.

VILELA NJ; HENZ GP. 2000. Situação atual da participação das hortaliças no agronegócio brasileiro e perspectivas futuras. Caderno de Ciência e Tecnologia 17: 71-89. 